\title{
Chalcone, Acyl Hydrazide, and Related Amides Kill Cultured Trypanosoma brucei brucei
}

\author{
Linda Troeberg, ${ }^{1}$ Xiaowu Chen, ${ }^{2}$ Terrence M. Flaherty, ${ }^{2}$ Rory E. Morty, ${ }^{1}$ \\ Maosheng Cheng, ${ }^{2}$ Huiming Hua, ${ }^{2}$ Clayton Springer, ${ }^{2}$ James H. McKerrow, $^{2,3}$ \\ George L. Kenyon, ${ }^{2}$ John D. Lonsdale-Eccles, ${ }^{1}$ Theresa H. T. Coetzer, ${ }^{1}$ \\ and Fred E. Cohen, ${ }^{4,5}$ \\ ${ }^{1}$ School of Molecular and Cellular Biosciences, University of Natal \\ (Pietermaritzburg), Scottsville, South Africa \\ ${ }^{2}$ Departments of Pharmaceutical Chemistry and \\ ${ }^{3}$ Pathology, Veterans Affairs Medical Center, University of California, \\ San Francisco, California, U.S.A. \\ ${ }^{4}$ Departments of Biochemistry and Biophysics and \\ ${ }^{5}$ Pharmacology and Medicine, University of California, San Francisco, \\ California, U.S.A. \\ Communicated by F. E. Cohen. Accepted May 12, 2000
}

\begin{abstract}
Background: Protozoan parasites of the genus Trypanosoma cause disease in a wide range of mammalian hosts. Trypanosoma brucei brucei, transmitted by tsetse fly to cattle, causes a disease (Nagana) of great economic importance in parts of Africa. T. b. brucei also serves as a model for related Trypanosoma species, which cause human sleeping sickness.

Materials and Methods: Chalcone and acyl hydrazide derivatives are known to retard the growth of Plasmodium falciparum in vitro and inhibit the malarial cysteine proteinase, falcipain. We tested the effects of these compounds on the growth of bloodstream forms of T. b. brucei in cell culture and in a murine trypanosomiasis model, and investigated their ability to inhibit trypanopain-Tb, the major cysteine proteinase of $T . b$. brucei.

Results: Several related chalcones, acyl hydrazides,
\end{abstract}

and amides killed cultured bloodstream forms of T. b. brucei, with the most effective compound reducing parasite numbers by $50 \%$ relative to control populations at a concentration of $240 \mathrm{nM}$. The most effective inhibitors protected mice from an otherwise lethal T. $b$. brucei infection in an in vivo model of acute parasite infection. Many of the compounds also inhibited trypanopain-Tb, with the most effective inhibitor having a $K_{i}$ value of $27 \mathrm{nM} . K_{i}$ values for trypanopain-Tb inhibition were up to 50- to 100fold lower than for inhibition of mammalian cathepsin L, suggesting the possibility of selective inhibition of the parasite enzyme.

Conclusions: Chalcones, acyl hydrazides, and amides show promise as antitrypanosomal chemotherapeutic agents, with trypanopain-Tb possibly being one of their in vivo targets.

\section{Introduction}

Trypanosoma brucei brucei is the causative agent of bovine trypanosomiasis (also known as Na-

Address Correspondence to: Theresa H. T. Coetzer, Departments of Cellular and Molecular Pharmacology, Medicine, Pharmaceutical Chemistry and Biochemistry $\delta$ Biophysics, University of California, San Francisco, CA 94143-0446. Phone: 415-476-8519; Fax: 415-476-6516; E-mail: cohen@cgl.ucsf.edu gana), a disease of great economic importance in many parts of Africa. It renders an estimated one quarter of Africa unsuitable for livestock farming (1), with the total economic impact of the disease in the range of US\$5 billion annually (2). T. $b$. brucei infection is also a suitable model for human trypanosomiasis (sleeping sickness) caused by the related parasites T. $b$. gambiense and T. $b$. rhodesiense. The emergence of drug-resistant 
trypanosome strains, coupled with the toxicity and limited efficacy of the current treatment methods, have prompted the search for more effective antitrypanosomal agents.

The cysteine proteinases of several parasites have received attention as potential targets for chemotherapeutic intervention. Previous studies have shown that $T$. $b$. brucei is killed in vitro by cysteine proteinase inhibitors $(3,4)$, and T. cruzi (5) and T. congolense (6) are killed by cysteine proteinase inhibitors. Additionally, the growth and development of Schistosoma mansoni (7), Plasmodium vinckei (8), P. falciparum (9), Leishmania major (10) and T. cruzi $(5,11,12)$ are all inhibited by cysteine proteinase inhibitors. We therefore sought to investigate the effects of new classes of cysteine proteinase inhibitors on T. b. brucei.

Li et al. (13) showed that chalcone (1,3diphenyl-2-propen-one) derivatives inhibit the major cysteine proteinase of P. falciparum (falcipain) and inhibit growth of both chloroquineresistant and -sensitive P. falciparum. Chalcones have also been shown to be active against various Leishmania species $(10,14)$. Earlier studies by Ring et al. (15) and Li et al. (16) demonstrated the efficacy of bis aryl acyl hydrazides against $P$. falciparum and falcipain. Molecular modeling of falcipain allowed structure-based selection of potentially more effective chalcone and hydrazide derivatives guided by the program DOCK (17). Here we report that several members of these families of compounds are trypanocidal against cultured bloodstream forms of T. b. brucei and that those compounds most effective in vitro were able to combat experimental T. $b$. brucei infections in mice. Several of the compounds inhibited purified trypanopain-Tb, mirroring their effectiveness against falcipain $(13,15,16)$. However, no direct correlation was observed between trypanocidal activity and inhibition of purified trypanopain$\mathrm{Tb}$, suggesting that these compounds may have additional targets within the parasite.

\section{Materials and Methods}

Minimal essential medium (MEM) with Earle's salts, bathocuproine disulfonic acid, penicillin/ streptomycin mixture, dimethyl sulfoxide (DMSO), L-trans-epoxysuccinyl-leucylamido(4-guanidino)-butane (E-64), and carbobenzoxy (Z)-Phe-Arg-aminomethyl coumarin (AMC) were from Sigma Chemical Co. (St. Louis, Mo.).
Fetal calf serum was from Delta BioProducts (Kempton Park, South Africa). Cell culture prefilters $(0.45 \mu \mathrm{m})$ were from Corning (Staffordshire, U.K.) and $0.22-\mu \mathrm{m}$ filter units were from Millipore (Bedford, MA). Sterilized cell culture pipettes (10 and $1 \mathrm{ml})$ and sterile Petri dishes (50-mm diameter) were from Bibby Sterilin (Staffordshire, U.K.). All aldehydes, methyl ketones, and acyl hydrazides were purchased from Adrich Chemical Co. (Milwaukee, WI) and used without further purification.

Chemical Syntheses and Calculation of Log P Values

General Procedure for the Preparation of Chalcones A substituted aldehyde ( $1 \mathrm{mmol}$ ) and a substituted methyl ketone $(1 \mathrm{mmol})$ were dissolved in a minimal amount of methanol (3-5 ml). A sodium hydroxide pellet (approximately $100 \mathrm{mg}$ ) was added to the solution. Precipitates formed within a few minutes to 24 $\mathrm{hr}$. The solution was filtered and the precipitate washed with cold methanol $(3 \times 10 \mathrm{ml})$. Products were recrystallized from appropriate solvents whenever necessary.

General Procedure for the Preparation of Acyl Hydrazides A substituted aldehyde (1 mmol) and a substituted acyl hydrazine (1 mmol) were dissolved in methanol $(20 \mathrm{ml})$. The solution was heated at reflux. Precipitates formed within a few minutes to several hours. The solution was filtered and the precipitate washed with hot methanol $(3 \times 10 \mathrm{ml})$. Products were recrystallized from appropriate solvents whenever necessary. Chemical purity was confirmed by NMR.

General Procedure for the Preparation of $\alpha, \beta$ Unsaturated Amides A $50-\mathrm{ml}$ round bottom flask charged with an aldehyde $(1.0 \mathrm{mmol})$, malonic acid (1.0 mmol), piperidine (0.1 mmol), and pyridine $(15 \mathrm{ml})$ was heated at reflux for $4 \mathrm{hr}$. The solution was cooled and poured onto ice. The solid was filtered and washed with water to provide an $\alpha, \beta$-unsaturated acid. To a stirred solution of the acid $(1.0 \mathrm{mmol})$ in dimethyl formamide $(10 \mathrm{ml})$ was added bezotriazol-1-yloxy-tris(dimethylamino) phosphonium hexafluorphosphate (1.1 mmol), diisopropylethylamine $(2.0 \mathrm{mmol})$, and an amine $(1.5 \mathrm{mmol})$. After $18 \mathrm{hr}$, the solution was partitioned between ethyl acetate and water. 
The organic phase was collected, dried (on $\mathrm{Na}_{2} \mathrm{SO}_{4}$ ), and evaporated. The crude product was purified by flash chromatography using hexanes/acetone as the eluent.

Calculation of $\log P$ Values of Chalcones, Acyl Hydrazides, and Amides

The log of the partition coefficient, $P$, between octanol and water $(\log P)$ for the compounds, which serves as an indication of their hydrophobicity, was calculated using the software CLogP 4.51 (Daylight Chemical Information Systems, Santa Fe, NM), which is an implementation of the prescription stated in (18).

Effect of Chalcones, Acyl Hydrazides, and Amides on Growth of Cultured T. b. brucei

Bloodstream forms of T. b. brucei (clone IL-Tat 1.1) were grown in Petri dishes in MEM with Earle's Salts supplemented with 0.25 mM cysteine, $0.01 \mathrm{mM}$ bathocuproine disulfonic acid, $15 \%(\mathrm{v} / \mathrm{v})$ heat-inactivated fetal calf serum, and penicillin/streptomycin in a $95 \%$ humidified atmosphere, containing 5\% (v/v) $\mathrm{CO}_{2}$ at $37^{\circ} \mathrm{C}(19)$. Various concentrations of each tested compound (in $2.5 \mu \mathrm{l}$ DMSO, with final concentrations between $0.8-20 \mu \mathrm{M}$ ) were added to T. b. brucei in MEM $(2.5 \mathrm{ml})$ in Petri dishes (duplicate dishes for each concentration of compound) and the number of motile trypanosomes counted (twice from each Petri dish) after $24 \mathrm{hr}$ using a hemocytometer. Control trypanosome populations were treated with DMSO alone. Plots of compound concentration versus the number of live trypanosomes were prepared and the concentration reducing parasite numbers to $50 \%$ of that of the control population determined (defined as the $I C_{50}$ ). The error on the gradient of this line was calculated and was less than $10 \%$ in all cases.

\section{In Vivo Testing of Chalcones and Hydrazides}

Three compounds showing greatest trypanocidal effectiveness in vitro were further tested in vivo. The toxicity of the chalcone (MC161) and hydrazides (ZLIII43A and ZLIV44A) was first evaluated by injecting adult Balb/c mice $(n=3)$ intraperitoneally with a single dose of $100 \mu \mathrm{l}$ of phosphate/saline/glucose (PSG; $57 \mathrm{mM}$ $\mathrm{NaH}_{2} \mathrm{PO}_{4}, 57 \mathrm{mM} \mathrm{Na}_{2} \mathrm{HPO}_{4}, 46 \mathrm{mM} \mathrm{NaCl}, 56 \mathrm{mM}$ glucose, $0.1 \mathrm{mM}$ hypoxanthine, $\mathrm{pH} 8.0$ ) and $25 \mu \mathrm{l}$ of DMSO containing $2 \mathrm{mg}$ ( $100 \mathrm{mg} / \mathrm{kg}$ body mass) of compound. Subsequently, another group of mice $(n=3)$ were injected daily for 5 days with $100 \mu \mathrm{l} \mathrm{PSG}$ and $25 \mu \mathrm{l}$ of DMSO containing $0.5 \mathrm{mg}$ of compound ( $25 \mathrm{mg} / \mathrm{kg}$ body mass).

The effect of the compounds on experimental T. $b$. brucei infection was investigated by injecting mice ( $n=8$ for each group) intraperitoneally with trypanosomes $(5,000$ parasites in $100 \mu \mathrm{l}$ of PSG) and immediately afterward with $25 \mu \mathrm{l}$ of compound $(0.5 \mathrm{mg}, 50 \mathrm{mg} / \mathrm{kg}$ body mass) in DMSO. Control mice were injected with $100 \mu$ l trypanosomes (5,000 trypanosomes) and $25 \mu \mathrm{l}$ of DMSO alone.

The effects of delayed administration of the compounds were tested by injecting mice $(n=$ 8 in each group) intraperitoneally with $T$. b. brucei $(5,000$ parasites in $100 \mu \mathrm{l}$ of PSG) and $3 \mathrm{hr}$ later with compound $(0.5 \mathrm{mg}$ in $25 \mu \mathrm{l}$ DMSO, $25 \mathrm{mg} / \mathrm{kg}$ body mass). Controls received trypanosomes and $25 \mu \mathrm{l}$ of DMSO alone.

In each case, parasitemia was monitored twice daily by examination of wet blood films of blood taken from the tail vein.

\section{Enzyme Isolation and Assay}

Trypanopain-Tb was purified from bloodstream T. $b$. brucei (clone ILTat 1.1) using three-phase partitioning and ion exchange chromatography on Q-Sepharose (20). The enzyme was assayed at $25^{\circ} \mathrm{C}$ in $200 \mathrm{mM}$ sodium phosphate buffer, pH 7.0, containing $2 \mathrm{mM} \mathrm{Na}_{2}$ EDTA and $30 \mathrm{mM}$ cysteine (20) with Z-Phe-Arg-AMC (final concentration $5 \mu \mathrm{M}, \operatorname{Ex} 370 \mathrm{~nm}, \mathrm{Em} 460 \mathrm{~nm}$ ) as the substrate.

Sheep cathepsin L, purified from sheep liver (21), was assayed against $5 \mu \mathrm{M}$ Z-PheArg-AMC (22) using $340 \mathrm{mM}$ sodium acetate buffer, pH 5.5, containing $60 \mathrm{mM}$ acetic acid, $4 \mathrm{mM} \mathrm{Na}{ }_{2}$ EDTA, $4 \mathrm{mM}$ dithiothreitol, pH 5.5.

The active concentrations of both enzymes were determined by titration against E-64 (23).

\section{Determination of Equilibrium Constant for Inhibition $\left(\mathrm{K}_{\mathrm{i}}\right)$}

Initial studies showed that the activity against the fluorogenic substrate Z-Phe-Arg-AMC of both trypanopain- $\mathrm{Tb}$ and cathepsin $\mathrm{L}$ was reduced by micromolar concentrations of chalcones, hydrazides, and amides. Additionally, this inhibition was shown to be reversible because dilution reduced the observed percentage of inhibition (results not shown). $K_{i}$ was 
thus calculated from three separate continuous assays by comparing the rates of Z-Phe-ArgAMC hydrolysis in the absence and presence of chalcones, hydrazides, or amides. Enzyme (either trypanopain-Tb or cathepsin L, $3 \mathrm{ng}, 0.1$ pmol, $240 \mu \mathrm{l}$ ) was activated in prewarmed assay buffer $\left(25^{\circ} \mathrm{C}, 5 \mathrm{~min}, 500 \mu \mathrm{l}\right)$, Z-Phe-ArgAMC $(5 \mu \mathrm{M}, 250 \mu \mathrm{l})$ added and the initial rate of substrate hydrolysis $\left(\mathrm{v}_{\mathrm{o}}\right)$ determined. Inhibitor $(0.1-10 \mathrm{nmol}$ in $10 \mu \mathrm{l}$ DMSO, 0.1-100 $\mu \mathrm{M}$ final concentration) was added at several thousand-fold molar excess over the enzyme (first-order conditions; 24) and the inhibited reaction rate $\left(\mathrm{v}_{\mathrm{i}}\right)$ determined. Mean $K_{i} \pm \mathrm{SD}$ $(n=3)$ was then calculated from the equation,

$$
K_{i}=\frac{[\mathbf{l}]}{\frac{S_{\mathrm{o}}}{v_{i}}-\mathbf{1}} / \mathbf{1}+\frac{[s]}{k_{m}} I
$$

Because chalcones, acyl hydrazides, and amides are competitive inhibitors, the concentration of both the substrate (S) and the inhibitor (I) were considered. The affinity between substrate and enzyme was accounted for by inclusion of the Michaelis constant for hydrolysis of Z-Phe-Arg-AMC $\left(K_{m}\right)$, which is 1.2 $\mu \mathrm{M}$ for trypanopain- $\mathrm{Tb}(20)$ and $6.81 \mu \mathrm{M}$ for cathepsin L (25).

\section{Results}

\section{Effect of Chalcones, Hydrazides, and Amides} on Growth of Cultured T. $b$. brucei

Several chalcones, hydrazides and amides reduced growth of bloodstream forms of T. $b$. brucei in culture at micromolar concentrations (Tables 1, 2, and 3). A comparison of the $I C_{50}$ for each inhibitor, defined as the inhibitor concentration that reduces parasite numbers to $50 \%$ of that of the control population, identified the most active compounds in the chalcone, acyl hydrazide, and amide series. MC161 was the most trypanocidal in the chalcone series with an $I C_{50}$ value of $0.24 \mu \mathrm{M}$, while in the hydrazide series, MC357 $(0.42 \mu \mathrm{M})$, TF-1-52 $(0.58 \mu \mathrm{M})$, and ZLIV44A $(0.72 \mu \mathrm{M})$ exhibited $I C_{50}$ values below $1 \mu \mathrm{M}$. The amide series was less effective with the best $I C_{50}$ values that of BG31A02 (1.82 $\mu \mathrm{M})$, BG21A11, HH27A43 and HH29A43 (4.4 $\mu \mathrm{M})$.
The most active chalcones and acyl hydrazides $\left(I C_{50}<1 \mu \mathrm{M}\right)$ and amides $\left(I C_{50}<4.5 \mu \mathrm{M}\right)$ have CLogP values below 5 (Tables 1, 2 and 3); that is, MC161 (3.05), MC375 (4.296), TF1-52 (3.865), ZLIV44A (3.317), BG31A02 (4.721), BG21A11 (3.203), HH27A43 (4.101), HH29A43 (1.610), and HH25A43 (1.104), suggesting that they will have good absorption properties and membrane permeability (26).

Effect of Chalcones and Hydrazides on $\mathrm{T}$. $\mathrm{b}$. brucei Infection in Mice

Three of the compounds with highest trypanocidal activity were chosen for testing in vivo, against a murine T. b. brucei infection. All three tested compounds have CLogP values below 5 and would therefore be sufficiently membrane soluble to act as drugs in vivo. The toxicity of the chalcones and hydrazides was first evaluated by injecting adult Balb/c mice intraperitoneally with a single dose of compound of 2 $\mathrm{mg}$ ( $100 \mathrm{mg} / \mathrm{kg}$ body mass). Subsequently, another group of mice were injected with $0.5 \mathrm{mg}$ compound daily for 5 days $(25 \mathrm{mg} / \mathrm{kg}$ body mass). Both experiments showed the compounds to be nonlethal to adult Balb/c mice, although mice appeared slightly bloated and photosensitive for 1 week following administration.

The effect of these compounds on experimental T. $b$. brucei infection was initially investigated by injecting mice intraperitoneally with a lethal dose of trypanosomes and immediately afterward with $0.5 \mathrm{mg}$ of tested compound (50 mg/kg body mass). Control mice were injected with trypanosomes alone and died on day $7.17 \pm 1.33$. All mice treated with $\mathrm{MCl} 161$ and ZLIII43A survived, with no parasites evident in their bloodstream a month after infection. Of those treated with ZLIV44A, five survived and three died (on day $5.33 \pm 0.56$ ).

To test the effects of delayed administration of these compounds, mice were injected intraperitoneally with a lethal dose of T. $b$. brucei and $3 \mathrm{hr}$ later with compound $(0.5 \mathrm{mg}, 25$ $\mathrm{mg} / \mathrm{kg}$ body mass). Controls received trypanosomes alone and died on day $4.43 \pm 1.13$. ZLIII43A was ineffective, with treated mice dying at the same time as the controls (day 4.38 $\pm 0.74)$. Mice treated with ZLIV44A lived for $18 \%$ longer than the controls, dying on day $5.22 \pm 0.83$, while mice treated with MC161 lived $47 \%$ longer than the controls, dying on day $6.5 \pm 2.07$. 
Table 1. Effects of chalcones on cultured T. b. brucei, purified trypanopain-Tb, and sheep cathepsin $L$

\begin{tabular}{|c|c|c|c|c|c|c|}
\hline Compound & $\mathbf{A}$ & B & CLogP & $\begin{array}{l}\text { T. b. brucei } \\
I C_{50}(\mu \mathrm{M})\end{array}$ & $\begin{array}{l}\text { Trypanopain } \\
\quad K_{i}(\mu \mathrm{M})^{a}\end{array}$ & $\begin{array}{c}\text { Cathepsin L } \\
K_{i}(\mu \mathrm{M})^{a}\end{array}$ \\
\hline MC153 & & $F$ & 3.295 & 4.79 & $\mathrm{NI}^{b}$ & $12.11 \pm 1.41$ \\
\hline MC135 & & $\mathrm{Cl}$ & 4.245 & 5.49 & NI & $9.55 \pm 1.42$ \\
\hline MC131b & & $\mathrm{Cl}$ & 5.252 & 13.80 & $0.37 \pm 0.06$ & $7.16 \pm 0.62$ \\
\hline MC151 & & $F$ & 4.302 & 9.07 & $9.65 \pm 0.91$ & $9.48 \pm 1.59$ \\
\hline MC159 & & $\mathrm{Cl}$ & 4.455 & 3.52 & NI & $4.57 \pm 0.55$ \\
\hline JD 159 & & $\mathrm{Cl}$ & 4.115 & 1.88 & $17.14 \pm 1.76$ & $6.95 \pm 0.80$ \\
\hline MC161 & & & 3.505 & 0.24 & NI & $40.72 \pm 4.81$ \\
\hline MC 143 & & & 5.937 & 3.50 & $2.25 \pm 0.29$ & $2.66 \pm 0.62$ \\
\hline
\end{tabular}

${ }^{a}$ Data reflect the mean $K_{i} \pm \mathrm{SD}(n=3)$.

${ }^{b}$ No inhibition. 
Table 2. Effects of hydrazide derivatives on cultured T. b. brucei, purified trypanopain-Tb, and sheep cathepsin $\mathbf{L}$

\begin{tabular}{|c|c|c|c|c|c|c|}
\hline Compound & $\mathbf{A}$ & B & CLogP & $\begin{array}{l}\text { T. b. brucei } \\
I C_{50}(\mu \mathrm{M})\end{array}$ & $\begin{array}{l}\text { Trypanopain } \\
K_{i}(\mu \mathbf{M})^{a}\end{array}$ & $\begin{array}{c}\text { Cathepsin } \mathbf{L} \\
K_{i}(\mu \mathrm{M})^{a}\end{array}$ \\
\hline ZLIV44A & & & 3.317 & 0.72 & $1.31 \pm 0.20$ & $9.48 \pm 0.52$ \\
\hline ZLIII43A & & $\mathrm{OH}$ & 4.226 & 1.53 & $0.027 \pm 0.002$ & $1.49 \pm 0.17$ \\
\hline ZLIII115A & & $\mathrm{OH}$ & 5.755 & 1.01 & $0.34 \pm 0.04$ & $0.90 \pm 0.14$ \\
\hline MC357 & $\mathrm{OH}$ & $\mathrm{OH}$ & 4.296 & 0.42 & $0.64 \pm 0.08$ & $1.07 \pm 0.14$ \\
\hline TF-1-58 & & $\mathrm{OH}$ & 2.215 & 1.44 & $1.20 \pm 0.01$ & $6.47 \pm 1.18$ \\
\hline TF-1-52 & & $\mathrm{OH}$ & 3.865 & 0.58 & $1.12 \pm 0.24$ & $1.59 \pm 0.31$ \\
\hline TF-1-54 & & $\mathrm{OH}$ & 4.255 & 2.34 & $3.45 \pm 0.27$ & $3.18 \pm 0.48$ \\
\hline TF-1-56 & & $\mathrm{OH}$ & 6.523 & 1.66 & $0.22 \pm 0.06$ & $1.90 \pm 0.10$ \\
\hline TF-1-51 & & $\mathrm{OH}$ & 4.273 & 1.55 & $4.47 \pm 0.64$ & $1.52 \pm 0.28$ \\
\hline
\end{tabular}




\begin{tabular}{|c|c|c|c|c|c|c|}
\hline Compound & $\mathbf{A}$ & B & CLogP & $\begin{array}{l}\text { T. b. brucei } \\
I C_{50}(\mu \mathbf{M})\end{array}$ & $\begin{array}{l}\text { Trypanopain } \\
\qquad K_{i}(\mu \mathbf{M})^{a}\end{array}$ & $\begin{array}{c}\text { Cathepsin L } \\
K_{i}(\mu \mathbf{M})^{a}\end{array}$ \\
\hline TF-1-59 & & & 4.063 & 2.14 & $1.38 \pm 0.14$ & $3.81 \pm 0.59$ \\
\hline TF-1-53 & & & 4.376 & 2.70 & $2.74 \pm 0.44$ & $3.39 \pm 0.31$ \\
\hline TF-1-55 & & & 5.070 & 1.91 & $4.06 \pm 0.66$ & $2.32 \pm 0.16$ \\
\hline TF-1-60 & & & 4.632 & 1.02 & $0.39 \pm 0.12$ & $1.35 \pm 0.21$ \\
\hline
\end{tabular}

${ }^{a}$ Data reflect the mean $K_{i} \pm$ SD $(n=3)$.

Inhibition of Purified Trypanopain-Tb and Cathepsin $L$

Chalcones, hydrazides and amides effectively inhibited trypanopain-Tb and cathepsin L, with $K_{i}$ values in the low micromolar and high nanomolar range (Tables 1,2 , and 3 ). The rate of association $\left(k_{\text {ass }}\right)$ between the enzymes and chalcones, hydrazides, or amides was too fast for accurate determination without a stoppedflow apparatus. Inhibition of trypanopain-Tb, together with their antiparasitic action, mirrors these compounds' previously reported effectiveness against Leishmania (10) and Plasmodium (15).

\section{Discussion}

Several of the tested chalcones, hydrazides, and amides effectively killed cultured T. $b$. brucei at micromolar concentrations. Taken in conjunction with previous reports of their effectiveness against Leishmania $(10,14)$ and Plasmodium $(13,15,16)$, this report suggests that these compounds have potential as broad-range antiparasitic agents. We also show in this study that these compounds can act systemically, combating an experimental trypanosome infection, if given at the time of infection. The reduction in efficacy upon delayed administration is thought to be a function of concentration. That is, when the compounds are co-administered with the trypanosomes into the peritoneum, the effective concentration of compound reaching the parasites is higher than if the compounds are administered when the parasites have already migrated from the peritoneum into the bloodstream. Future developments in formulation will include enhancing aqueous solubility of the compounds and optimizing the dosing regimen.

It is not clear how chalcones, hydrazides, and amides kill T. b. brucei or related parasites. Because they inhibit purified trypanopain-Tb (this study) and falcipain $(13,15,16)$ in vitro, it is tempting to speculate that they kill T. b. brucei by inhibiting this enzyme. However, because they are reversible inhibitors of trypanopain$\mathrm{Tb}$, it is not possible to confirm trypanopain- $\mathrm{Tb}$ as an intracellular target by labeling the inhibitors and identifying the covalently linked enzyme/inhibitor complex. Additionally, chalcones have also been shown to inhibit glutathione reductase (27) and have been suggested as possible trypanothione reductase 
Table 3. Effects of amide derivatives on cultured $T$. b. brucei, purified trypanopain-Tb, and sheep cathepsin $\mathbf{L}$<smiles>[Y]C=CC(=O)N[B]</smiles>

\begin{tabular}{|c|c|c|c|c|c|c|}
\hline Compound & $\mathbf{A}$ & B & CLogP & $\begin{array}{l}\text { T. b. brucei } \\
I C_{50}(\mu \mathbf{M})\end{array}$ & $\begin{array}{l}\text { Trypanopain } \\
K_{i}(\mu \mathrm{M})^{a}\end{array}$ & $\begin{array}{l}\text { Cathepsin } \mathbf{L} \\
K_{i}(\mu \mathbf{M})^{a}\end{array}$ \\
\hline MC24A24 & & & 5.276 & 28.56 & $0.61 \pm 0.09$ & $11.52 \pm 1.38$ \\
\hline MC24A4I & & & 5.746 & 11.82 & $1.06 \pm 0.15$ & $3.25 \pm 0.62$ \\
\hline MC23A24 & & & 5.276 & 10.00 & $0.26 \pm 0.04$ & $1.42 \pm 0.14$ \\
\hline MC08A27 & & & 5.498 & 13.50 & $0.66 \pm 0.11$ & $13.01 \pm 1.49$ \\
\hline BG31A02 & $=$ & & 4.721 & 1.82 & $0.50 \pm 0.08$ & $52.17 \pm 3.43$ \\
\hline BG21A11 & & & 3.203 & 4.44 & $\mathrm{NI}^{b}$ & $61.07 \pm 7.54$ \\
\hline HH27A43 & & & 4.101 & 4.40 & $1.49 \pm 0.24$ & $16.09 \pm 3.94$ \\
\hline HH29A43 & & & 1.610 & 4.40 & NI & $20.49 \pm 1.87$ \\
\hline HH25A43 & & & 1.140 & 4.72 & NI & $49.70 \pm 11.32$ \\
\hline
\end{tabular}

${ }^{a}$ Data reflect the mean $K_{i} \pm \mathrm{SD}(n=3)$.

${ }^{b}$ No inhibition.

inhibitors (14). We observed no direct correlation between trypanocidal activity and inhibition of purified trypanopain-Tb, supporting the suggestion that trypanopain-Tb is not the major target of these compounds in vivo. Thus, although MC161 has the lowest $I C_{50}$ value against cultured T. b. brucei, it does not inhibit trypanopain-Tb at $100 \mu \mathrm{M}$.

Inhibition of host cathepsins has been one of the predicted major stumbling blocks to the therapeutic use of cysteine proteinase inhibitors. For in vivo use, a cysteine proteinase inhibitor should ideally be entirely specific for its target enzyme and not crossreact with related host enzymes. Although this has been difficult to achieve in practice, the inhibitors tested in this study were able to discriminate between trypanopain-Tb and cathepsin L to some degree. The amide BG31A02 and the acyl hydrazide ZLIII43A were 104 and 55 times more effective against trypanopainTb than against cathepsin L, respectively. 
Salvesen and Nagase (24), however, suggest that to suppress the activity of a single proteinase in vivo, the selective inhibitor should have a $K_{i}$ for the enzyme 1000-fold less than for any other enzyme in the mix, or a $k_{\text {ass }} 1000$-fold greater than for any other proteinase in the mix. The inhibitors we tested in vivo clearly do not fit these criteria, but nevertheless showed limited toxicity in vivo. T. $b$. brucei parasites live in the bloodstream of the host and therefore are more accessible to inhibition by bloodborne inhibitors than mammalian cysteine proteinases that reside in the lysosomes of cells. T. cruzi is also known to selectively accumulate fluoromethyl peptide inhibitors (28). Furthermore, because of host cysteine proteinase redundancy, cathepsin $L$ inhibition may not be lethal to mammalian cells. Using ZLIII43A as a starting point, compounds with increased selectivity are currently being investigated.

Although trypanopain-Tb has not been unequivocally identified as the intracellular target of the tested compounds, they do inhibit the purified enzyme and are effective antitrypanosomal agents in vivo and in culture. Chalcones, hydrazides, and amides have potential as antitrypanosomal agents. They are inexpensive to synthesize, and thus potentially of use in the developing world. The major disadvantage of these inhibitors is their low water solubility, but attempts to improve this are under way. Other cysteine proteinase inhibitors, namely fluoromethylketones, diazomethylketones, and chloromethylketones, are known to kill parasites $(4,7-9,12,29,30)$, but any potential clinical use of these inhibitors is limited by their toxicity and short in vivo half lives. The potential of less toxic cysteine proteinase inhibitors as antiparasitic agents has recently been clearly demonstrated by Engel et al. (5) who cured an experimental T. cruzi infection in mice using vinyl sulfones. Chalcones, hydrazides, and amides are not peptide based and are thus likely to have good in vivo half lives. Their in vitro antileishmanial $(10,14)$ and antimalarial (15) activity suggest that these compounds may have wide-ranging antiparasitic action in addition to their trypanocidal activity described here.

\section{Acknowledgments}

This work was supported by grants from the South African Foundation for Research Devel- opment and the University of Natal Research Fund (THTC), a Tropical Disease Research Unit Grant from the U.S. National Institute of Allergy and Infectious Diseases, and the Burroughs Wellcome Molecular Parasitology Scholar Award (JHMK).

\section{References}

1. Hall HTB. (1977) Disease and Parasites of Livestock in the Tropics. Longman, Harlow.

2. International Laboratory for Research on Animal Diseases. (1994) ILRAD 1993/4: Annual Report of the International Laboratory for Research on Animal Diseases. International Laboratory for Research on Animal Diseases, Nairobi, pp. 21-29.

3. Troeberg L, Morty RE, Pike RN, et al. (1999) Cysteine proteinase inhibitors kill cultured bloodstream forms of Trypanosoma brucei brucei Exp. Parsitol. 91: 349-355.

4. Ashall F, Angliker H, Shaw E. (1990) Lysis of trypanosomes by peptidyl fluoromethyl ketones. Biochim. Biophys. Res. Comm. 70: 923-929.

5. Engel JC, Doyle PS, Hsieh I, McKerrow JH. (1998) Cysteine proteinase inhibitors cure an experimental Trypanosoma cruzi infection. J. Exp. Med. 188: 725-734.

6. Mbawa ZR, Gumm ID, Shaw E, LonsdaleEccles JD. (1992) Characterisation of a cysteine protease from bloodstream forms of Trypanosoma congolense. Eur. J. Biochem. 204: 371-379.

7. Wasilewski MM, Lim KC, Phillips J, McKerrow JH. (1996) Cysteine protease inhibitors block schistosome hemoglobin degradation in vitro and decrease worm burden and egg production in vivo. Mol. Biochem. Parasitol. 81: 179-189.

8. Rosenthal PJ, Lee GK, Smith RE. (1993) Inhibition of a Plasmodium vinckei cysteine proteinase cures murine malaria. J. Clin. Invest. 91: 10521056.

9. Rockett KA, Playfair JHL, Ashall F, Targett GAT, Angliker H, Shaw E. (1990) Inhibition of intraerythrocytic development of Plasmodium falciparum by proteinase inhibitors. FEBS Lett. 259: 257-259.

10. Selzer PM, Chen X, Chan VJ, et al. (1997) Leishmania major: molecular modeling of cysteine proteases and prediction of new non-peptide inhibitors. Exp. Parasitol. 87: 212-221.

11. Harth G, Andrews N, Mills AA, Engel JC, Smith R, McKerrow JH. (1993) Peptidefluoromethyl ketones arrest intracellular replication and intercellular transmission of Trypanosoma cruzi. Mol. Biochem. Parasitol. 58: 17-24.

12. Mierelles MNL, Juliano L, Carmona E, et al. (1992) Inhibitors of the major cysteinyl proteinase 
(GP57/51) impair host cell invasion and arrest the intracellular development of Trypanosoma cruzi in vitro. Mol. Biochem. Parasitol. 52: 175-184.

13. Li R, Kenyon GL, Cohen FE, et al. (1995) In vitro antimalarial activity of chalcones and their derivatives. J. Med. Chem. 38: 5031-5037.

14. Torres-Santos EC, Moreira DL, Kaplan MAC, Meirelles MN, Rossi-Bergman B. (1999) Selective effect of 2', 6'-dihydroxy-4'-methylchalcone isolated from Piper aduncum on Leishmania amazonensis. Antimicrob. Agents Chemother. 43: 1234-1241.

15. Ring CS, Sun E, McKerrow JH, et al. (1993) Structure-based inhibitor design by using protein models for the development of antiparasitic agents. Proc. Natl. Acad. Sci. U. S. A. 90: 3583-3587.

16. Li Z, Chen X, Davidson E, et al. (1994) Antimalarial drug development using models of enzyme structure. Chem. Biol. 1: 31-37.

17. Kuntz ID. (1992) Structure-based strategies for drug design and discovery. Science 257: 1078-1082.

18. Hansch C, Leo AJ. (1979) In: Substituent Constants for Correlation Analysis in Chemistry and Biology. Wiley Interscience, New York.

19. Hesse F, Selzer PM, Mühlstädt K, Duszenko M. A novel cultivation technique for long-term maintenance of bloodstream form trypanosomes in vitro. Mol. Biochem. Parasitol. 70: 157-166.

20. Troeberg L, Pike RN, Morty RE, Berry RK, Coetzer THT, Lonsdale-Eccles JD. (1996) Proteases from Trypanosoma brucei brucei: purification, characterisation and interactions with host regulatory molecules. Eur. J. Biochem. 238: 728-736.

21. Pike RN, Coetzer THT, Dennison C. (1992) Proteolytically active complexes of cathepsin L and a cysteine proteinase inhibitor; purification and demonstration of their formation in vitro. Arch. Biochem. Biophys. 294: 623-629.
22. BarrettAJ, Kirschke H. (1981). Cathepsin B, cathepsin H and cathepsin L. Methods Enzymol. 80C: $535-561$.

23. Barrett AJ, Kembhavi AA, Brown MA, et al. (1982) L-trans-epoxysuccinyl-leucylamido(4guanidino) butane (E-64) and its analogues as inhibitors of cysteine proteinases including cathepsins B, H and L. Biochem. J. 201: 189-198.

24. Salvesen G, Nagase K. (1989). Inhibition of proteolytic enzymes, p. 83-104. In: Benyon RJ, Bond JS (eds.) Proteolytic Enzymes: A Practical Approach. IRL Press, Oxford.

25. Dehrmann FM, Coetzer THT, Pike RN, Dennison C. (1995) Mature cathepsin L is substantially active in the ionic milieu of the extracellular medium. Arch. Biochem. Biophys. 324: 93-98.

26. Lipinski CA, Lombardo F, Dominy BW, Feeny PJ. (1997) Experimental and computational approaches to estimate solubility and permeability in drug discovery and development settings. Adv. Drug Delivery Rev. 23: 3-25.

27. Zhang K, Yang EB, Tang YW, Wong KP, Mack P. (1991) Inhibition of glutathione reductase by plant polyphenols. Biochem. Pharmacol. 54: 1047-1053.

28. McKerrow JH, McGrath ME, Engel JC. (1995) The cysteine protease of Trypanosoma cruzi as a model for antiparasitic drug design. Parasitol. Today 11: 279-282.

29. de Cazzulo F, MartInez BMJ, North MJ, Coombs MH, Cazzulo J-J. (1994) Effects of proteinase inhibitors on growth and differentiation of Trypanosoma cruzi. FEMS Microbiol. Lett. 124: 81-86.

30. Rosenthal PJ, McKerrow JH, Rasnick D, Leech JH. (1989) Plasmodium falciparum: inhibitors of lysosomal cysteine proteinases inhibit a trophozoite proteinase and block parasite development. Mol. Biochem. Parasitol. 35: 177-184. 